\title{
LA "REINTERPRETACIÓN CONSTITUCIONAL" DE LA APRECIACIÓN EN CONCIENCIA DE LA LECrim. ESPAÑOLA
}

\author{
THE "CONSTITUTIONAL REITERPRETATION" OF AWARENESS APPRECIATION ON \\ THE SPANISH CRIMINAL PROCEDURE LAW
}

Fecha de Recepción: 04/03/2011

Fecha de Aceptación: 07/03/2011

Dr. David Vallespín Pérez ${ }^{1}$

\begin{abstract}
Resumen:
El presente artículo se centra en el análisis de los diferentes sistemas de valoración de la prueba en el proceso penal, con especial atención a la correcta interpretación, en el marco de un modelo constitucional de juicio justo, del principio de la "apreciación en conciencia" o "íntima conviccción" que consagra la Ley de Enjuiciamiento Criminal Española.
\end{abstract}

Palabras clave: Prueba, valoración probatoria, apreciación en conciencia

\section{Summary:}

This article is focused on the analysis of the different evidence evaluation systems in the criminal trial, with special attention to the correct interpretation, within a constitutional model of fair trial, of the "apreciación en conciencia" (appreciation in conscience) or "íntima convicción" (intimate belief) principle estabilished in the Spanish code of Criminal Procedure.

Key words: Evidence, Evaluation of evidence, Appreciation in conscience

\footnotetext{
Profesor Titular de Derecho Procesal de la Universidad de Barcelona. Catedrático Habilitado de Derecho Procesal. Facultad de Derecho de la Universidad de Barcelona. Departamento de Derecho Administrativo y Derecho Procesal de la Facultad de Derecho de la Universidad de Barcelona. Avda.Diagonal, 684, 08034, BARCELONA. Correo: dvallespin@ub.edu
} 


\section{Introducción}

La prueba procesal no va encaminada a demostrar la "verdad" de una afirmación ${ }^{2}$, sino que persigue lograr la "convicción judicial" acerca de la exactitud de las afirmaciones previamente realizadas. Como ya puso de relieve $\mathrm{WACH}^{3}$, "todas las pruebas judiciales no son más que grados de verosimilitud cuyo destinatario es el Juez", quien deberá proceder a su valoración en el momento de dictar sentencia ${ }^{4}$.

La valoración o apreciación probatoria incluye en su interior dos operaciones relacionadas entre sí, pero diferentes: la interpretación, como actuación previa que tiene por objeto conocer jurídicamente lo que la prueba dice o quiere decir; y la valoración en sentido estricto, como aquella operación, subsiguiente a la interpretación, en virtud de la cual se procede a dar o negar crédito a las pruebas ${ }^{5}$.

En concreto, la mayoría de las afirmaciones sobre los hechos que las partes realizan están necesitadas de prueba ${ }^{6}$, por lo que, como ha señalado Sentís Melendo ${ }^{7}$, no resulta nada extraño que, históricamente, hayan aparecido dos grandes sistemas de valoración probatoria: el de valoración legal o tasada, que supone la existencia de normas o reglas en las que el legislador fija el valor a asignar a los distintos medios de prueba, limitándose el juzgador a aplicarlas para declarar probados o improbados unos determinados hechos ${ }^{8}$; y el de valoración judicial, que encuentra un especial caldo de cultivo en los criterios filosóficos de la llustración, y según el cual el juz-

2 Devis Echandía, Hernando, Contenido, naturaleza y técnica de valoración de la prueba judicial /en/ Revista de Derecho Procesal Iberoamericana, No 1, 1966, p. 10.

3 Wach, Adolf, Vörtrage, $2^{\text {a }}$ ed., Bonn, 1896.

4 Bentham, Jeremy, Tratado de las pruebas judiciales, I, traducción del francés a cargo de M. Osorio, Ejea, Buenos Aires, 1959, pp. 22-23; Carnelutti, Francesco, Lezioni sul processo penale, I, Edizioni dell'Ateneo, Roma, 1946, p. 209.

5 Con seguimiento de las conclusiones apuntadas por Calamandrei, Piero, La genesi logica della sentenza civile, en Opere Giuridiche, VI, Morano Editore, Napoli, 1965, pp. 20-21; véanse, entre otros: Abel Lluch, Xavier, Valoración de los medios de prueba en el proceso civil, en Realismo jurídico y Experiencia procesal, Liber amicorum al Prof. Dr. Serra Domínguez, dirigido por Ramos Méndez, Atelier, Barcelona, 2009, p. 71; Montero Aroca, Juan, La valoración de la prueba como garantía en el proceso civil, III Congreso Panameño de Derecho Procesal, Instituto Colombo de Derecho Procesal, 2006, pp. 421 424; Montón Redondo, Alberto, Valoración de la prueba e interpretación de los resultados probatorios, /en/ Revista de Derecho Procesal Iberoamericana, No 2-3, 1978, p. 384; y Vallespín Pérez, David, La valoración de la prueba en el proceso penal, /en/ Revista Argentina de Derecho Procesal, No 5, 2000, pp. 432-433.

6 Serra Domínguez, Manuel, Contribución al estudio de la prueba, en sus Estudios de Derecho Procesal, Barcelona, Ariel, 1969, p. 359 (también publicado en Revista Jurídica de Catalunya, 1962, pp. 317 y ss.; y ahora recogido, recientemente, en Estudios de Derecho Probatorio, Communitas, Lima, 2009, p. 29).

7 Sentís Melendo, Santiago, Valoración de la prueba /en/ Revista de Derecho Procesal Iberoamericana, № 2-3,1976, pp. 267 y ss. Para un análisis más reciente de los sistemas de valoración de la prueba, véase: Nieva Fenoll, Jordi, La valoración de la prueba, Marcial Pons, Madrid-Barcelona, 2009.

8 Cafferata Nores, José, La prueba en el proceso penal, Depalma, Buenos Aires, 1986, p. 40. 
gador formará su convicción con arreglo a su conciencia, es decir, valorando en su conjunto y libremente, sin sujeción a norma de ninguna especie que coarte su función psíquica, el resultado de los medios de prueba que se hayan practicado en el proceso ${ }^{9}$.

\section{El principio de la "íntima convicción" o de la libre valoración de la prueba. Planteamiento histórico y difusión}

El sistema de prueba libre que representa, como muy gráficamente señaló en su día Alcalá-Zamora, el reverso de la prueba legal o tasada, surge, como resultado de la impresión general que experimenta todo entendimiento ilustrado en presencia de las pruebas producidas ante sí mismo, de la "íntima convicción" del juez.

Este sistema -que encuentra su primera manifestación en Roma, donde el juez dispuso de una libertad absoluta para la apreciación de la prueba, hasta el punto de que podía suspender el pronunciamiento de la sentencia si estimaba que le faltaban elementos ${ }^{10}$ - quedó en suspenso en el Medievo; continuó así a lo largo del Renacimiento; resurgió con ímpetu por influencia directa del movimiento filosófico de la Ilustración ${ }^{11}$; y terminó por imponerse con su difusión por toda Europa bajo distintas fórmulas: 'intime conviction' en el Código de Instrucción Criminal francés, 'libero convencimento' en el Código italiano, y "apreciación en conciencia", como principio propio del sistema acusatorio formal o mixto que viene consagrado de forma expresa en el art. 741.1 de la LECrim. española de 1882: "el Tribunal dictará la sentencia, apreciando según su conciencia las pruebas prácticas en el juicio, las razones expuestas por la acusación y defensa y lo manifestado por los mismos procesados" - la ley no establece regla alguna para la apreciación de las pruebas, ya que el juez es libre de convencerse, según su íntimo parecer, de la existencia o inexistencia de los hechos de la causa, valorando las pruebas según su "leal saber y entender".

Ahora bien, la incorporación del método de la "íntima convicción", propio del sistema francés, no se acompañó de una total uniformidad en cuanto a su alcance en todos aquellos ordenamientos procesales penales que recibieron su influencia directa.

\footnotetext{
Fenech Navarro, Miguel, Derecho Procesal Penal, I, 3ª ed., Editorial Labor, Barcelona-Madrid, 1960, p. 613.

10 Florian, Eugene, Elementos de Derecho Procesal Penal, traducción de Prieto-Castro, Bosch, Barcelona, 1934, pp. 332-333.

11 Leone, Giovanni, Tratado de Derecho Procesal Penal, II, Desenvolvimiento del Proceso Penal. El Proceso de Primera Instancia, con traducción de Sentís Melendo, Ejea, Buenos Aires, 1963, p. 155; Nobili, Massimo, Il principio del libero convencimento del giudice, Giuffrè, Milano, 1974, pp. 145 y ss.; Vallespín Pérez, David, La valoración de la prueba en el proceso penal, obr.cit. pp. 438-439.
} 
Así, las fórmulas italiana (libero convencimento) y española ("apreciación en conciencia"), en sus orígenes, fueron deudoras de la jurisprudencia francesa, al negarse todo posible control de la valoración realizada por el juez ante otro superior.

En Inglaterra, por el contrario, en atención a las llamadas "leyes de la prueba" o "leyes de la evidencia", criterios objetivos de control y mesura de la libertad del juzgador a la hora de formar su convicción, se presta atención a un conjunto de criterios negativos en función de los cuales se puede excluir que puedan ser tomadas en consideración determinadas pruebas que de antemano tienen reconocida una tacha legal ${ }^{12}$.

Finalmente, algunos otros sistemas procesales penales, como el alemán, pueden calificarse de intermedios entre la fórmula pura francesa -acogida en Italia y Españay la realidad inglesa, pues en atención a la fórmula jurisprudencial creada bajo el principio de la "freie Beweiswürdigung", no solo se elimina el subjetivismo judicial, sino que, además, se permite al órgano judicial tomar en cuenta una prueba libre, pero correctamente entendida como libertad de estimación moral o racional ${ }^{13}$.

\section{La "apreciación en conciencia" de la LECrim española. Su significado originario y la exasperación jurisprudencial del principio}

Ante la costumbre tan arraigada de los jueces y tribunales españoles de dar escaso o ningún valor a las pruebas del plenario, buscando primar casi exclusivamente la verdad en las diligencias sumariales practicadas a espaldas del acusado, la Ley de Enjuiciamiento Criminal española de 1882 (art. 741), con el mismo tenor literal que ya incorporaba el art. 653 de la Ley de Enjuiciamiento Criminal de 1872, optó por considerar que los magistrados debían mantenerse a lo largo y ancho de la discusión pasivos, limitándose a dirigir con ánimo sereno los debates y a fallar de modo imparcial, sin sujetarse a pruebas tasadas a priori por la propia ley, sino con seguimiento libre de las particulares inspiraciones de su conciencia.

De este modo, la "apreciación en conciencia" vino a significar en la práctica, incluso tras la aprobación de la Constitución española de 1978, una facultad libérrima del juzgador en orden a apreciar las pruebas sin sometimiento no ya solo a las normas, sino tampoco a los dictados o reglas de la sana crítica o de la razón. Tan es así, que el Tribunal Supremo sintió una especial preocupación por dejar a salvo el principio de que la valoración probatoria corresponde soberanamente al órgano judicial

12 Giuliani, Alessandro, Problemi metodologici nello studio del diritto processuale comparato /en/ Rivista Trimestralle di Diritto e Procedura Civile, 1962, pp. 653 y ss.

13 Kern, Eduar. Stratverfharensrecht, Berlín, 1953, pp. 52 y ss. 
que juzga en la instancia, quien debería gozar de libertad omnímoda en esta delicada y fundamental tarea ${ }^{14}$.

Este modo de entender el principio de la "apreciación en conciencia", como es lógico, no resulta en absoluto coherente con el obligado respeto de aquellas aspiraciones a las que debe dar respuesta un proceso penal moderno influido por la construcción de un modelo constitucional de juicio justo o con todas las garantías ${ }^{15}$. Por el contrario, el alcance absolutamente libérrimo y omnímodo por parte del juzgador al valorar las pruebas resulta patológico, pues es incompatible con el obligado respeto, en un Estado social y democrático de Derecho, del principio del control en el proceso penal.

El principio de "apreciación en conciencia" de las pruebas está reñido con el de "juicio según conciencia", en el sentido de utilizar el juez su saber privado o su particular información extraprocesal para fundar en él su decisión. El juez puede convencerse o no libremente, en conciencia, pero únicamente utilizando para lograr ese convencimiento los materiales procesales, que no son otros que aquellos que han ingresado correctamente en el proceso y con las recíprocas garantías de las partes ${ }^{16}$.

Aun cuando la expresión "en conciencia" pueda sugerir una operación íntima o secreta, las reglas del "criterio racional" deben especificarse pasando a integrar la motivación de la sentencia (art. 120 CE). El principio de la "apreciación en conciencia" debe analizarse bajo el respeto de los criterios de "racionalidad" y "objetividad", pues cuando un ser humano es juzgado por otro ser humano, dicho juicio debe acometerse con su propia medida, y esta es la de un ser racional ${ }^{17}$.

14 A título de ejemplo, la STS, de 15 de marzo de 1978 (Art. 417), proclamó de forma expresa que: "el juzgador, a la hora de apreciar las pruebas practicadas, lo hará no ya sin reminiscencias de valoración tasada o predeterminada por la ley, o siguiendo los criterios de la sana crítica, sino de un modo tan libérrimo y omnímodo que no tiene más freno a su soberana facultad valorativa que el de proceder con arreglo a su propia conciencia".

15 Vázquez Sotelo, José Luis, "Presunción de inocencia" del imputado e "íntima convicción" del Tribunal, Bosch, Barcelona, 1984, pp. 466 y ss. En este mismo sentido, resulta especialmente gráfica la Sentencia de Tribunal Constitucional 31/1981, de 28 de julio (BOE. 13 de agosto), Sala Primera. Recurso de amparo: 113/1980. Ponente: Gloria Begué Cantón; que supuso un auténtico revulsivo en la práctica de los órganos judiciales españoles, ya que a partir de ella, en atención al derecho fundamental a la presunción de inocencia, se hizo necesario acometer, entre otras cosas, la "reinterpretación constitucional" de la apreciación en conciencia de la LECrim.

16 Salvioli, Giussepe, Le prove legali secondo la dottrina piu antica /en/ Rivista Giuridica d'Italia, Milano, Hoepli, VIII, $2^{\text {a }}$ parte, 1927, pp. 25 y ss.

17 Bertolino, Pedro, La "convicción sincera" como regla para la valoración de la prueba en los juicios penales (A propósito del nuevo Código Procesal Penal de la Provincia de Buenos Aires - Argentina), en La Prueba. Libro Homenaje al Maestro Devis Echandía, Universidad Libre - Instituto Colombiano de Derecho Procesal, Colombia, 2002, p. 275; Martínez Pereda, José Manuel, El convencimiento en el proceso penal español /en/ Revista de Derecho Judicial, enero-marzo, 1963, pp. 43. 
Dr. David Vallespín Pérez

\section{El principio de la "apreciación en conciencia" y su "reinterpre- tación constitucional". El sistema de la "persuasión racional"}

La interpretación histórica del principio de "libre valoración de la prueba", en la que se toma en consideración la libertad de valoración como no sujeción a criterio alguno, no solo a criterios establecidos legalmente, sino ni siquiera a los de un raciocinio correcto, comporta, por una parte, consecuencias negativas como la ausencia de toda explicación de la valoración realizada y también la de un posterior control sobre la misma; y, por otra, no se puede compaginar con el significado más genérico de la potestad de juzgar, que el art. 117.3 CE atribuye a los órganos jurisdiccionales y que consiste en una "operación racional que no solo tiene por objeto las normas jurídicas, sino también los hechos a los que éstas se aplican".

Frente a quienes han optado por defender que el órgano judicial en el momento de apreciar las pruebas lo haga solo en función de su conciencia, sin atadura alguna, ni siquiera de las reglas de la lógica o del criterio racional, resulta oportuno señalar que el juzgador al apreciar las pruebas "según su conciencia" deber proceder igual que antes lo hacía el legislador en el sistema de la prueba legal o tasada, es decir, aplicando en cada caso los criterios que la lógica, la ciencia y la experiencia así le enseñan ${ }^{18}$.

El sistema de la libre valoración, correctamente entendido, no quiere decir en modo alguno que el juzgador sea libre de seguir sus "caprichos", "impresiones" o "sospechas", sino que debe proceder a una deducción lógica, partiendo de unos datos fijados con certeza. Por ello, la "íntima convicción" del órgano judicial no puede resultar nunca equivalente a "despotismo", "capricho" o "arbitrariedad"19.

En esta dirección de pensamiento, es justo reconocer la importancia de la STS, de 15 de diciembre de $1981^{20}$, en la que se incorporan las líneas maestras del principio de la "íntima convicción", rectamente entendido, como principio que implica "valoración en conciencia", pero siempre con racionalidad: "... la valoración de la prueba es competencia exclusiva y excluyente del Tribunal llamado a fallar en la instancia sobre los hechos del proceso, sopesando la resultancia del juicio oral...; fijando los hechos probados "según su conciencia", es decir, ateniéndose no a principios de prueba legal o tasada, sino a las reglas del criterio racional, pues aquella expresión

18 Vázquez Sotelo, José Luis, obr.cit. pp. 483-484.

19 De Luca, Giuseppe, Il sistema delle prove penali e il principio del libero convencimento nel nuovo rito /en/ Rivista di Diritto e Procedura Penale, 1992, p. 1255; Deganello, Mario I criteri di valutazione della prova penale. Scenari di diritto giurisprudenziale, Giappichelli Editore, Torino, 2005, pp. 17 y ss.; Gimeno Sendra, Vicente, Derecho Procesal Penal, Colex, Madrid, 2007, pp. 113-114; Pérez-Cruz Martín, Agustín, et al., Derecho Procesal Penal, Thomson Reuters - Civitas, 2010, pp. 493-494.

20 STS de 15 de diciembre de 1981 (Art. 5009). 
más que a una apreciación íntima o secreta se está refiriendo a una operación regida por la lógica, con rechazo para todo lo que no pase de ser mera impresión, sospecha o conjura".

Esta Sentencia, como otras posteriores que Ilegan a nuestros días ${ }^{21}$, ha optado por consagrar, acertadamente, una concepción "argumentativa y dialéctica" de la prueba, sometida a criterios valorativos "racionales" y "lógicos". De este modo, el principio de la "apreciación en conciencia", correctamente entendido y aplicado, debe entenderse como "apreciación libre, pero con objetividad"22. Ello es así, porque la valoración de la prueba en el proceso penal no está desprovista de reglas a tomar en consideración, si bien estas no son suministradas por el legislador, sino por los criterios de la experiencia, la lógica, la razón, la vida misma, las ciencias y las técnicas especializadas (vg. la psicología experimental aplicada al proceso) ${ }^{23}$.

El libre convencimiento del juez no supone, por tanto, un estatus de discrecionalidad o arbitrariedad de su función, pues el derecho fundamental a la presunción de inocencia opera como un eficaz freno frente a un desmedido e injustificado ejercicio del arbitrio judicial. En consecuencia, la estimación "en conciencia" no ha de entenderse o hacerse equivalente a cerrado o inabordable criterio personal o íntimo del juzgador, sino a una operación lógica de la prueba, no exenta de pautas o directrices de rango objetivo. Así entendida la "libre valoración", que necesita de un sustrato probatorio y no puede recaer sobre simples diligencias de instrucción ${ }^{24}$, no impide la utilización del mecanismo deductivo de los "indicios", siempre que se explicite, como es lógico, el razonamiento seguido ${ }^{25}$.

21 Por todas, véanse, la STS de 18 de abril de 1988 (Art. 2800); la STS de 4 de abril de 1989 (Art. 3014); STS de 20 de noviembre de 2001 (RJ. 2781/2002); la STS de 23 de junio de 2005 (RJ. 6599); y la STS de 9 de diciembre de 2008 (RJ. 1373/2009).

22 Álvaro de Oliveira, Carlos Alberto, Livre apreciacâo da prova: perspectivas atuais, en La Prueba. Homenaje al Maestro Hernando Devis Echandía, Universidad Libre - Instituto Colombiano de Derecho Procesal, Colombia, 2002, pp. 599 y ss.: Barona Vilar, Silvia, Valoración libre de la prueba (Lección 13a), en Derecho Jurisdiccional, III, El Proceso Penal, Tirant lo Blanch, Valencia, 2008, pp. 314-315; Moreno Catena, Víctor, Valoración de la prueba (Lección $23^{\text {a }}$ - El desarrollo del juicio oral. La Prueba), en Derecho Procesal Penal, Valencia, Tirant lo Blanch, Valencia, 2005, p. 386.

23 STC de 18 de diciembre de 2003 (Pleno) - RTC 229/2003; STC de 11 de diciembre de 2006 (Sala Primera) - RTC 340/2006.

24 Ramos Méndez, Francisco, Enjuiciamiento criminal. Novena lectura constitucional, Atelier, Barcelona, 2010, p. 329. Sobre las consecuencias que derivan de la "preterición del juicio oral" y de la formación de la "convicción en el sumario", véase, por todos: Lorca Navarrete, Antonio María, Materiales para una necesaria y urgente reforma de la Ley de Enjuiciamiento Criminal en orden a la superación de su modelo acusatorio formal, Instituto Vasco de Derecho Procesal, San Sebastián, 2005, pp. 151 y ss.

25 STC de 17 de diciembre de 1985 (RTC 174/1985). Sala Primera; STC de 21 de mayo de 2009 (RTC 120/2009). Sala Primera. 
La etapa "científica" de la prueba, caracterizada por la idea central de recibir y valorar las pruebas con auxilio de los métodos científicos que puedan ser aplicados ${ }^{26}$, debe vincularse también con la correcta comprensión del principio de la "apreciación en conciencia". Ello obedece a que el carácter científico de las pruebas no debe oscurecer la figura central del juzgador, convirtiéndose el proceso en una especie de laboratorio dominado por la técnica. Una regulación procesal penal que siguiese estas directrices, como es fácil comprender, incurriría en los excesos propios del "cientifismo", en atención a los cuales se llegaría a instaurar un autoritarismo procesal moderno de tipo tecnocrático, similar en cuanto a sus efectos negativos a los propios de las épocas de la "prueba legal" o de valoración de forma "libérrima e irracional"27.

Ante la realidad que se acaba de describir -obligado respeto del modelo constitucional de juicio justo en el momento de valorar las pruebas y peligros propios del "cientifismo" - no resulta nada extraño que se defienda un nuevo método de valoración probatoria caracterizado por la "libertad de apreciación de forma objetiva y responsable".

Este sistema de valoración de la prueba, que ha sido denominado, muy agudamente, por el Prof. Vázquez Sotelo ${ }^{28}$, como de la "persuasión racional", viene caracterizado, en cuanto sistema "intermedio", por ser contrario tanto al método tarifario de las pruebas legales, como al planteamiento de la íntima convicción como operación puramente subjetiva, inmotivada e incontrolable del órgano judicial.

Este nuevo sistema, el de la "persuasión racional", supone acometer la valoración de las pruebas en libertad, pero bajo el obligado respeto de los imperativos suministrados por la lógica, la razón y la experiencia. De esta forma, sin llegar a coartar el libre convencimiento del juez, se procede a la depuración de los tópicos y extralimitaciones que lo han presidido a lo largo de la historia ${ }^{29}$.

26 Denti, Vittorio, Scientificità della prova e libera valutazione del giudice /en/ Rivista di Diritto Processuale, 1972, p. 416.

27 Denti, Vittorio, Cientificidad de la prueba, en relación principalmente con los dictámenes periciales y la libertad de apreciación del juzgador /en/ Revista de Derecho Procesal Iberoamericana, № 2-3, 1972; Devis Echandía, Hernando, Cientificidad de la prueba, en relación principalmente con los dictámenes periciales y la libertad de apreciación del juzgador /en/ Revista de Derecho Procesal Iberoamericana, No 1, 1972, p. 47; Gorphe, François, La apreciación judicial de las pruebas, traducción de AlcaláZamora, Ejea y Bosch editores, Buenos Aires, 1950, p. 9.

28 Vázquez Sotelo, Jose Luis, obr.cit. p. 466.

29 Igartua Salaverría, Juan, Desventuras de la íntima convicción. Estudios de jurisprudencia, Revista Colex, núm. 7, 1993, pp. 7, nota 3. 


\section{Bibliografía}

Abel Lluch, Xavier, Valoración de los medios de prueba en el proceso civil, en Realismo jurídico y Experiencia procesal, Liber amicorum al Prof. Dr. Serra Domínguez, dirigido por Ramos Méndez, Atelier, Barcelona, 2009.

Álvaro de Oliveira, Carlos Alberto, Livre apreciacão da prova: perspectivas atuais, en La Prueba. Homenaje al Maestro Hernando Devis Echandía, Universidad Libre Instituto Colombiano de Derecho Procesal, Colombia, 2002.

Barona Vilar, Silvia, Valoración libre de la prueba (Lección 13aa), en Derecho Jurisdiccional, III, El Proceso Penal, Tirant lo Blanch, Valencia, 2008.

Bentham, Jeremy, Tratado de las pruebas judiciales, I, traducción del francés a cargo de M. Osorio, Ejea, Buenos Aires, 1959.

Bertolino, Pedro, La "convicción sincera" como regla para la valoración de la prueba en los juicios penales (A propósito del nuevo Código Procesal Penal de la Provincia de Buenos Aires - Argentina), en La Prueba. Libro Homenaje al Maestro Devis Echandía, Universidad Libre - Instituto Colombiano de Derecho Procesal, Colombia, 2002.

Cafferata Nores, José, La prueba en el proceso penal, Depalma, Buenos Aires, 1986.

Calamandrei, Piero, La genesi logica della sentenza civile, en Opere Giuridiche, VI, Morano Editore, Napoli, 1965.

Carneluttı, Francesco, Lezioni sul processo penale, I, Edizioni dell'Ateneo, Roma, 1946.

De LuCA, Giuseppe, Il sistema delle prove penali e il principio del libero convencimento nel nuovo rito /en/ Rivista di Diritto e Procedura Penale, 1992.

Deganello, Mario I criteri di valutazione della prova penale. Scenari di diritto giurisprudenziale, Giappichelli Editore, Torino, 2005.

Denti, Vittorio, Cientificidad de la prueba, en relación principalmente con los dictámenes periciales y la libertad de apreciación del juzgador /en/ Revista de Derecho Procesal Iberoamericana, No 2-3, 1972.

DentI, VitTorio, Scientificità della prova e libera valutazione del giudice /en/ Rivista di Diritto Processuale, 1972.

Devis Echandía, Hernando, Cientificidad de la prueba, en relación principalmente con los dictámenes periciales y la libertad de apreciación del juzgador /en/ Revista de Derecho Procesal Iberoamericana, № 1, 1972.

Devis Echandía, Hernando, Contenido, naturaleza y técnica de valoración de la prueba judicial /en/ Revista de Derecho Procesal Iberoamericana, № 1, 1966.

Fenech Navarro, Miguel, Derecho Procesal Penal, I, $3^{\text {a }}$ ed., Editorial Labor, BarcelonaMadrid, 1960. 
Florian, Eugene, Elementos de Derecho Procesal Penal, traducción de Prieto-Castro, Bosch, Barcelona, 1934.

Gimeno Sendra, Vicente, Derecho Procesal Penal, Colex, Madrid, 2007.

Giuliani, Alessandro, Problemi metodologici nello studio del diritto processuale comparato /en/ Rivista Trimestralle di Diritto e Procedura Civile, 1962.

Gorphe, Françols, La apreciación judicial de las pruebas, traducción de Alcalá-Zamora, Ejea y Bosch editores, Buenos Aires, 1950.

Igartua Salaverría, Juan, Desventuras de la íntima convicción. Estudios de jurisprudencia, Revista Colex, núm. 7, 1993.

KerN, Eduar. Stratverfharensrecht, Berlín, 1953.

Leone, Giovanni, Tratado de Derecho Procesal Penal, II, Desenvolvimiento del Proceso Penal. El Proceso de Primera Instancia, con traducción de Sentís Melendo, Ejea, Buenos Aires, 1963.

lorca Navarrete, Antonio María, Materiales para una necesaria y urgente reforma de la Ley de Enjuiciamiento Criminal en orden a la superación de su modelo acusatorio formal, Instituto Vasco de Derecho Procesal, San Sebastián, 2005.

Martínez Pereda, José Manuel, El convencimiento en el proceso penal español /en/ Revista de Derecho Judicial, enero-marzo, 1963.

Montero Aroca, JuAN, La valoración de la prueba como garantía en el proceso civil, III Congreso Panameño de Derecho Procesal, Instituto Colombo de Derecho Procesal, 2006.

Montón Redondo, Alberto, Valoración de la prueba e interpretación de los resultados probatorios/en/ Revista de Derecho Procesal Iberoamericana, N²-3, 1978.

Moreno Catena, Víctor, Valoración de la prueba (Lección $23^{a}$ - El desarrollo del juicio oral. La Prueba), en Derecho Procesal Penal, Valencia, Tirant lo Blanch, Valencia, 2005.

Nieva FenolL, Jordı, La valoración de la prueba, Marcial Pons, Madrid-Barcelona, 2009.

Nobilı, Massimo, Il principio del libero convencimento del giudice, Giuffrè, Milano, 1974.

Pérez-Cruz Martín, Agustín, et al., Derecho Procesal Penal, Thomson Reuters - Civitas, 2010.

Ramos Méndez, Francisco, Enjuiciamiento criminal. Novena lectura constitucional, Atelier, Barcelona, 2010.

Salviolı, Giussepe, Le prove legali secondo la dottrina piu antica /en/ Rivista Giuridica d'Italia, Milano, Hoepli, VIII, $2^{\text {a }}$ parte, 1927. 
Sentís Melendo, Santiago, Valoración de la prueba /en/ Revista de Derecho Procesal Iberoamericana, No 2-3,1976.

Serra Domínguez, Manuel, Contribución al estudio de la prueba, en sus Estudios de Derecho Procesal, Barcelona, Ariel, 1969.

Vallespín Pérez, David, La valoración de la prueba en el proceso penal /en/ Revista Argentina de Derecho Procesal, No 5, 2000, pp. 432-433.

Vázquez Sotelo, José Luis, "Presunción de inocencia" del imputado e "íntima convicción" del Tribunal, Bosch, Barcelona, 1984.

WACH, Adolf, Vörtrage, $2^{a}$ ed., Bonn, 1896. 